\title{
Sweet Seizures - Epilepsia Partialis Continua
}

\author{
Ragesh Panikkath MD, Joaquin Abeal Lado MD
}

\begin{abstract}
Epilepsia partialis continua (EPC) refers to focal and recurrent seizures that happen every few seconds to minutes for extended periods of time. The most common causes of these seizures are stroke, Rasmussen's encephalitis (in children), and viral encephalitis. Metabolic disorders, like hyperglycemic hyperosmolar state (HHS), infrequently cause EPC. Correction of the HHS stops the EPC and eliminates the need for antiepileptic drugs. Synaptic transmission in the central nervous system requires normal glucose concentrations. Hyperglycemia can lower the seizure threshold, and this possibly explains the development of seizures in patients with HHS.
\end{abstract}

Key words: Hyperglycemic hyperosmolar state, epilepsia partialis continua, focal seizures, diabetes

\section{INTRODUCTION}

Epilepsia partialis continua (EPC) refers to focal and recurrent seizures that happen every few seconds to minutes for extended periods of time. Cerebrovascular stroke, Rasmussen's encephalitis, and viral encephalitis can cause EPC. ${ }^{1}$ Metabolic disorders can rarely cause EPC. ${ }^{1,2}$

\section{Case Presenttion}

A 65-year-old woman presented with recurrent involuntary movements of both upper extremities. This was disregarded as voluntary movements by the emergency room (ER) physician. However, these recurrent focal movements were consistent focal seizures. She was conscious and oriented and was conversing coherently during the episodes. Some of the episodes were followed by transient paralysis affecting the upper limbs. She had no prior history of seizures, and she denied any history of fever, alcohol use, or exposure to toxins or drugs. She had diabetes mellitus type 2 and had a plasma glucose of 814 $\mathrm{mg} / \mathrm{dl}$ and a negative serum acetone in the ER. The measured serum osmolality was $350 \mathrm{mOsm} / \mathrm{L}$. The involuntary movements stopped when euglycemia was reestablished. She had similar movements two days before this episode, when she was treated in the ER for hyperglycemia (plasma glucose $800 \mathrm{mg} / \mathrm{dl}$ ), and these movements also stopped after treatment of the hyperglycemia. An EEG (when euglycemic) and brain MRI were unremarkable. These recurrent focal seizures with short interictal periods, associated with Todd's paralysis, suggest that the patient had EPC precipitated by a hyperglycemic hyperosmolar state(HHS).

\section{Discussion}

EPC is considered a rare form of focal status epilepticus. ${ }^{3}$ Its characteristic features help differentiate it from other movement disorders and myoclonic 
jerks, and electrophysiology can confirm the cortical origin of these seizures. ${ }^{3}$ Childhood EPC is commonly caused by Rasmussen's encephalitis; vascular and neoplastic diseases are the usual causes in adults. Metabolic disorders (HHS, Alper's syndrome, toxic exposures, and mitochondrial disorders) account for $6-14 \%$ of cases with EPC. ${ }^{2,3}$ Twenty to thirty percent of patients have no identifiable cause. ${ }^{2,3}$ Hyperglycemia is a rare cause of seizures but is the most common reversible cause. ${ }^{3-5}$ However, this association is easily overlooked, or EPC may not be identified, as occurred in our patient during her initial presentation. EPC can also be the presenting symptom of diabetes. ${ }^{4}$ Increased metabolism of inhibitory neurotransmitter gamma amino butyric acid(GABA) leading to lower seizure thresholds has been proposed as one reason for seizures in these patients.

Experimental studies have demonstrated that a threshold glucose concentration is required for synaptic transmission. ${ }^{6,7}$ Both hyperglycemia and hypoglycemia can cause neuronal hyperexcitability and reduce the seizure threshold in experimental studies. ${ }^{7}$ Schwechter et al exposed slices of exposed rat endorhinal cortex-hippocampus to various concentrations of extracellular glucose and found enhanced burst amplitudes with an increase in glucose concentrations to $20 \mathrm{mM}(360 \mathrm{mg} / \mathrm{dl}){ }^{6}{ }^{6}$ The exact mechanism of neuronal hyperexcitability associated with hyperglycemia is unknown. Ketosis can also lower the seizure threshold. ${ }^{8}$ Correction of the underlying metabolic abnormality is the preferred treatment for these patients rather than antiepileptic drugs. This is especially important since phenytoin can worsen glycemic control which could predispose patients with diabetes to HHS and EPC. ${ }^{9}$

In addition to seizures, hyperglycemia/HHS can cause several other neurological abnormalities, including delirium, coma, and dyskinesias, such as hemiballismus and hemichorea. Dyskinesias are more common in Asians (86\% of reported cases). Potential causes include ischemia in the contralateral putamen and/or depletion of GABA. ${ }^{10}$ The hyperosmolar state could cause mild ischemia of the putamen, and hyperviscosity and hyperosmolality might damage the blood brain barrier leading to small petechial hemorrhages in the putamen..$^{10-12}$ This metabolic derangement also causes calcium deposition in the basal ganglia which could lead to more impairment. ${ }^{10}$ Hyperglycemia favors anaerobic metabolism at the cellular level. This depletes the acetoacetate in the cell which is a precursor substrate for the formation of GABA, an inhibitor of the dopaminergic neurons in the nigrostriatal pathway. Therefore, depletion of GABA leads to hyperdopaminergic state which initiates chorea. Post-menopausal women with estrogen deficiency are hypersensitive to dopamine, and this helps explain why the majority of cases occur in women in the ages $50-80$ years. ${ }^{10}$ These dyskinesias subside slowly with the correction of hyperglycemia, although some persist for months. CT of the head and the T1 weighted image of an MRI may show hyperdensity in the contralateral putamen and caudate nucleus.

Our patient had bilateral abnormal movements consistent with seizures (with postictal paralysis) and did not have any imaging abnormalities in the basal ganglia. The movements stopped with the achievement of euglycemia.

\section{Conclusions}

EPC is a rare form of focal seizures. Although $\mathrm{HHS}$ is an uncommon cause of EPC, it needs to be considered in the differential diagnosis when a patient presents with continuous focal seizures. Treatment aimed at correction of hyperglycemia helps control the seizure activity.

\section{Key PoInts}

1. Hyperglycemia is an under recognized cause of seizures.

2. Hyperglycemic hyperosmolar states (HHS) can be associated with epilepsia partialis continua.

3. Correction of HHS usually treats the EPC and avoids the need for antiepileptic drugs. 
Author Affiliation: Ragesh Panikkath is an Internal Medicine resident at TTUHSC in Lubbock, TX. Joaquin Abeal Lado is an endocrinologist in Department of Internal Medicine at TTUHSC in Lubbock, TX.

Received: 05/05/2013

Accepted: 05/27/2013

Reviewers: Cynthia Jumper MD, Zachary Mulkey MD

Published electronically: 07/15/2013

Conflict of Interest Disclosures: None
11. Chu K, Kang DW, Kim DE, Park SH, Roh JK. Diffusionweighted and gradient echo magnetic resonance findings of hemichorea-hemiballismus associated with diabetic hyperglycemia: a hyperviscosity syndrome? Arch Neurol. 2002;59:448-52. 12. Lai PH, Tien RD, Chang MH, Teng MM, Yang CF, Pan HB, Chen C, Lirng JF, Kong KW. Chorea-ballismus with nonketotic hyperglycemia in primary diabetes mellitus. AJNR Am J Neuroradiol. 1996;17:1057-64.

\section{REFERENCES}

1. Cockerell OC, Rothwell J, Thompson PD, Marsden CD, Shorvon SD. Clinical and physiological features of epilepsia partialis continua. Cases ascertained in the UK. Brain. 1996;119 ( Pt 2):393-407.

2. Sinha S, Satishchandra P. Epilepsia Partialis Continua over last 14 years: experience from a tertiary care center from south India. Epilepsy Res. 2007;74:55-9.

3. Bien CG, Elger CE. Epilepsia partialis continua: semiology and differential diagnoses. Epileptic Disord. 2008;10:3-7.

4. Singh BM, Strobos RJ. Epilepsia partialis continua associated with nonketotic hyperglycemia: clinical and biochemical profile of 21 patients. Ann Neurol. 1980;8:155-60.

5. Placidi F, Floris R, Bozzao A, Romigi A, Baviera ME, Tombini M, Izzi F, Sperli F, Marciani MG. Ketotic hyperglycemia and epilepsia partialis continua. Neurology. 2001;57:534-7.

6. Schwechter EM, Veliskova J, Velisek L. Correlation between extracellular glucose and seizure susceptibility in adult rats. Ann Neurol. 2003;53:91-101.

7. Stafstrom CE. Hyperglycemia Lowers Seizure Threshold. Epilepsy Curr. 2003;3:148-149.

8. Binder DK, Sarkissian V, Dillon WP, Weinstein PR. Spontaneous intracranial hypotension associated with transdural thoracic osteophyte reversed by primary. dural repair. Case report. $J \mathrm{Neu}$ rosurg Spine. 2005;2:614-8.

9. Carter BL, Small RE, Mandel MD, Starkman MT. Phenytoininduced hyperglycemia. Am J Hosp Pharm. 1981;38:1508-12.

10. Lin JJ, Chang MK. Hemiballism-hemichorea and non-ketotic hyperglycaemia. J Neurol Neurosurg Psychiatry. 1994;57:74850. 